Check for updates

Cite this: J. Anal. At. Spectrom., 2021, 36,1750

Received 11th June 2021

Accepted 16th July 2021

DOI: 10.1039/d1ja00205h

rsc.li/jaas

\title{
LA-ICP-MS using a nitrogen plasma source $\uparrow$
}

\author{
Christoph Neff, (D) Pascal Becker, (D) Bodo Hattendorf (D)* and Detlef Günther (D)*
}

Here we describe the first study of a nitrogen based inductively coupled plasma mass spectrometry system in conjunction with laser ablation ( $\left.L A-\left(N_{2}-I C P\right)-M S\right)$. Therefore, a microwave-sustained, inductively coupled, atmospheric-pressure plasma source was mounted onto the interface of a quadrupole ICP-MS to investigate the capabilities of such an instrument. The proof of concept study was focused on the quantification capabilities of major to trace elements. Therefore, the plasma background species under dry plasma conditions were investigated to identify the most suitable isotopes for the analysis and to describe the newly formed nitrogen plasma interferences. In addition, the instrumental drift was investigated. Selected elements in the reference materials NIST SRM 612 and BCR-2G were quantified using NIST SRM 610 as an external standard and could be determined within the uncertainty of the reference values. Finally, the limits of detection for $L A-\left(N_{2}-I C P\right)-M S$ and LA-(Ar-ICP)-MS were compared indicating similar or even lower LODs for most elements using LA- $\left(N_{2}-I C P\right)-M S$. Therefore, a nitrogen plasma source coupled to a mass spectrometer could challenge the argon-sustained ICP-MS in element analysis by overcoming argon interferences and has the potential to reduce the plasma gas expenses significantly.

\section{Introduction}

Laser ablation inductively coupled plasma mass spectrometry using argon-sustained plasma sources (LA-(Ar-ICP)-MS) ${ }^{1,2}$ has successfully been applied during the last decades for element analysis of solid samples. Especially the high sensitivity, low limits of detection (LODs) and the wide linear dynamic range made (Ar-ICP)-MS in combination with laser ablation a favourable technique to determine element compositions from major to trace elements. ${ }^{3}$ Despite the widely demonstrated applications of LA-(Ar-ICP)-MS, ${ }^{4-11}$ Ar plasma sources come with certain limitations. The consumption of almost $1 \mathrm{~m}^{3}$ of pure $\mathrm{Ar}$ gas per hour constitutes a substantial budget for its operation and gas blank species can interfere with major analyte isotopes. For example, the plasma species ${ }^{38} \mathrm{Ar}^{1} \mathrm{H}^{+},{ }^{40} \mathrm{Ar}^{+},{ }^{40} \mathrm{Ar}^{12} \mathrm{C}^{+},{ }^{36} \mathrm{Ar}^{16} \mathrm{O}^{+}$, ${ }^{38} \mathrm{Ar}^{14} \mathrm{~N}^{+},{ }^{40} \mathrm{Ar}^{15} \mathrm{~N}^{+},{ }^{40} \mathrm{Ar}^{14} \mathrm{NH}^{+},{ }^{40} \mathrm{Ar}^{16} \mathrm{O}^{+}$, and ${ }^{40} \mathrm{Ar}_{2}{ }^{+}$interfere with the most abundant isotopes of $\mathrm{K}, \mathrm{Ca}, \mathrm{Cr}, \mathrm{Mn}, \mathrm{Fe}$, and $\mathrm{Se}$, respectively. ${ }^{12-14}$ Furthermore, residues of Xe can interfere with the high abundance isotope of ${ }^{128} \mathrm{Te}^{+} \cdot{ }^{15,16}$ In consequence, the LODs are increased and in some cases limit the access to trace and ultra-trace levels. In addition, a number of argides are formed with matrix elements, which leads to additional spectral interferences. ${ }^{17}$ For example, the formation of ${ }^{40} \mathrm{Ar}^{35} \mathrm{Cl}^{+}$in chloride rich matrices interfere with ${ }^{75} \mathrm{As}^{18,19}$ or the formation of

Laboratory of Inorganic Chemistry, Department of Chemistry and Applied Biosciences, ETH Zurich, Vladimir-Prelog-Weg 1, 8093 Zürich, Switzerland. E-mail: detlef. guenther@sl.ethz.ch; bodo@inorg.chem.ethz.ch

$\dagger$ Electronic supplementary information (ESI) available. See DOI: 10.1039/d1ja00205h
${ }^{63} \mathrm{Cu}^{40} \mathrm{Ar}^{+}$and ${ }^{65} \mathrm{Cu}^{40} \mathrm{Ar}^{+}$when analysing copper ore interfere with ${ }^{103} \mathrm{Rh}^{+}$and ${ }^{105} \mathrm{Pd}^{+} .{ }^{20,21}$ Typically, these interferences can be mitigated by using ion molecule reactions in collision and reaction cell instruments or instruments with high mass resolving power as sector field ICP-MS. ${ }^{20,22,23}$

However, another approach to remove Ar based interferences is to replace the Ar plasma gas by $\mathrm{N}_{2}$. Several $\mathrm{N}_{2}$-sustained plasma sources have been developed for element analysis during the last 50 years. ${ }^{24-27}$ They allowed for significant reduction of Ar plasma species. In return, other species, especially based on $\mathrm{N}$ and $\mathrm{O}$ such as $\mathrm{N}^{+}, \mathrm{O}^{+}, \mathrm{N}_{2}{ }^{+}, \mathrm{O}_{2}{ }^{+}, \mathrm{NO}^{+}, \mathrm{N}_{3}{ }^{+}$, and $\mathrm{N}_{4}{ }^{+}$, were reported. ${ }^{13,19}$ However, coupled to MS they allowed the quantification of $\mathrm{K}, \mathrm{Ca}, \mathrm{Cr}, \mathrm{Fe}$, As and Se at lower LODs when compared to (Ar-ICP)-MS, but they suffered from low plasma power, plasma stability, and/or substantially higher LODs for other elements. ${ }^{13,28-30}$

A recent new development in this field is the microwavesustained, inductively coupled, atmospheric-pressure plasma (MICAP), ${ }^{31}$ which operates with $\mathrm{N}_{2}$ as the plasma gas at a plasma power of up to $1500 \mathrm{~W}$ while using a conventional Fassel-type ICP torch. ${ }^{32}$ In a first attempt, such a source was successfully implemented into commercially available ( $\mathrm{N}_{2}$-ICP)-OES systems. ${ }^{33,34}$ Later, this $\mathrm{N}_{2}$-ICP plasma source was also tested as an ion source for time-of-flight mass spectrometry. ${ }^{19}$ The latter report indicated that sensitivities for the ( $\mathrm{N}_{2}$-ICP)-MS were slightly lower in comparison to an (Ar-ICP)-MS, but the LODs for $\mathrm{K}, \mathrm{Ca}, \mathrm{Cr}, \mathrm{Fe}, \mathrm{As}$, and Se were substantially improved, while being comparable for most other elements. Using $\mathrm{N}_{2}$ as the plasma gas could not only compete with the performance of an (Ar-ICP)-MS, it could also constitute a more cost-effective 
alternative to the Ar-ICP. ${ }^{19}$ However, this proof of concept study was performed using liquid sample introduction, where aerosol desolvation was found to lead to substantial improvements in sensitivity.

To explore that further, we coupled the MICAP plasma source to a quadrupole mass spectrometer to investigate the capabilities of the high-power nitrogen plasma with dry aerosols from laser ablation sampling (LA-( $\mathrm{N}_{2}$-ICP)-MS). Therefore, we measured the gas blank species under dry plasma conditions, the element sensitivities and LODs. Furthermore, the long-term stability was evaluated. Finally, quantitative analyses were carried out using established glass standard materials (BCR-2G and NIST SRM 612) to demonstrate the capabilities of the nitrogen plasma source for major, minor and trace elements.

\section{Experimental}

\section{Instrumentation}

The prototype instrument consists of a MICAP (Radom Corp, USA) plasma source coupled to the interface of an ELAN 6100 DRC $^{\text {plus }}$ (PerkinElmer SCIEX, USA) instrument. The plasma was sustained with $\mathrm{N}_{2}$ cooling gas, $\mathrm{N}_{2}$ auxiliary gas, and $\mathrm{N}_{2}$ carrier gas, all from a liquid $\mathrm{N}_{2}$ Dewar $(>99.99 \%$, PanGas AG, Switzerland).

Laser ablation was performed using an argon-fluoride (ArF) excimer LA system (193 nm, GeoLas C, Lambda Physik, Germany) providing a homogenized, circular laser beam. The ablation took place in a cylindrical ablation cell with a gas inlet nozzle of $0.5 \mathrm{~mm}$ diameter. ${ }^{35}$ Helium (99.999\%, PanGas AG, Switzerland) served as the ablation gas. ${ }^{36}$ The background spectrum for an argon-sustained ICP-MS was acquired using an ELAN 6100 DRC $^{\text {plus }}$ (PerkinElmer SCIEX, USA). The quantification of NIST SRM 612 with LA-(Ar-ICP)-MS was performed using an Agilent 7500 cs (Agilent, USA).

\section{Samples}

The reference materials NIST SRM 610, NIST SRM 612, and BCR-2G were used to evaluate the capabilities of the LA- $\left(\mathrm{N}_{2}\right.$ ICP)-MS. ${ }^{37,38}$ NIST SRM 612 and BCR-2G were quantified using NIST SRM 610 as an external standard and ${ }^{40} \mathrm{Ca}^{+}$was used as internal standard. For each LA-( $\left.\mathrm{N}_{2}-\mathrm{ICP}\right)$-MS measurement, $30 \mathrm{~s}$ of gas blank were acquired followed by $50 \mathrm{~s}$ of ablation. LA-( $\mathrm{N}_{2}-$

Table 1 LA and $\left(\mathrm{N}_{2}-\mathrm{ICP}\right)$-MS operating parameter

Laser fluence

Laser repetition rate

Laser spot diameter

Ablation mode

Ablation gas flow (He)

Carrier gas flow $\left(\mathrm{N}_{2}\right)$

Auxiliary gas flow $\left(\mathrm{N}_{2}\right)$

Cooling gas flow $\left(\mathrm{N}_{2}\right)$

Plasma power

Sampler cone

Skimmer cone
$15-20 \mathrm{~J} \mathrm{~cm}^{-2}$

$10 \mathrm{~Hz}$

$60 \mu \mathrm{m}$

Hole-drilling (bulk analysis)

0.9-1.0 L min ${ }^{-1}$

$0.7-0.85 \mathrm{~L} \mathrm{~min}^{-1}$

$0.8 \mathrm{~L} \mathrm{~min}^{-1}$

$14 \mathrm{~L} \mathrm{~min}^{-1}$

$1500 \mathrm{~W}$

$1.1 \mathrm{~mm} \emptyset, \mathrm{Pt}$

$0.8 \mathrm{~mm} \emptyset, \mathrm{Pt}$
ICP)-MS operating conditions are given in Table 1. The quantification of NIST SRM 612 using LA-(Ar-ICP)-MS is described in the ESI and the operating conditions are given in ESI, Table S1. $\dagger$

\section{Data evaluation}

The quantification was performed using an in-house written Python-based software (Stalquant). ${ }^{39}$ The determination of the LODs, further data processing, and plots were performed using an in-house written script running on R. ${ }^{\mathbf{4 0 , 4 1}}$ Mass fractions and LODs were calculated according to Longerich et al. ${ }^{\mathbf{4 2}}$

\section{Results and discussion}

\section{Optimization}

The LA-( $\mathrm{N}_{2}$-ICP)-MS operating conditions were adjusted using NIST SRM 610 for high signal intensity from Li to U while maintaining a U/Th ratio of 0.9-1.1. A typical transient signal of six selected elements is displayed in Fig. 1a. In this case, intensity ratios of ${ }^{238} \mathrm{U}^{+} /{ }^{232} \mathrm{Th}^{+}=1.01,{ }^{232} \mathrm{Th}^{16} \mathrm{O}^{+} /{ }^{232} \mathrm{Th}^{+}=0.3 \%$, and ${ }^{232} \mathrm{Th}^{14} \mathrm{~N}^{+} /{ }^{232} \mathrm{Th}^{+}=0.2 \%$ were measured (Fig. 1b). These values indicated that the $\mathrm{N}_{2}$-ICP plasma source can provide similarly robust conditions as an argon-sustained plasma sources and very similar operating conditions apply. Especially, the close match of the ${ }^{238} \mathrm{U}^{+} /{ }^{232} \mathrm{Th}^{+}$intensity ratio with their molar ratio in NIST SRM $610\left({ }^{238} \mathrm{U} /{ }^{232} \mathrm{Th}=0.98\right)$ indicated similar vaporization efficiency of the laser-generated particles within the nitrogen plasma. ${ }^{43}$

\section{$\mathbf{N}_{2}$ plasma background species}

The plasma background spectra for dry ( $\mathrm{N}_{2}$-ICP)-MS and dry (ArICP)-MS are compared in Fig. 2. Especially in the mass range 35-107 $\mathrm{m} / \mathrm{z}$, the dry $\left(\mathrm{N}_{2}-\mathrm{ICP}\right)-\mathrm{MS}$ produced less atomic and molecular ion species that could interfere with analytes when compared to the (Ar-ICP)-MS, which is in line with earlier reports. ${ }^{19}$ The gas blank species in the $\left(\mathrm{N}_{2}\right.$-ICP)-MS for ${ }^{40} \mathrm{Ar}^{+}$, ${ }^{40} \mathrm{Ar}^{12} \mathrm{C}^{+},{ }^{38} \mathrm{Ar}^{14} \mathrm{~N}^{+},{ }^{36} \mathrm{Ar}^{16} \mathrm{O}^{+},{ }^{40} \mathrm{Ar}^{15} \mathrm{~N}^{+},{ }^{40} \mathrm{Ar}^{16} \mathrm{O}^{+},{ }^{40} \mathrm{Ar}_{2}{ }^{+}$and ${ }^{128} \mathrm{Xe}^{+}$were significantly reduced or even below the respective detection limits.

The dry ( $\mathrm{N}_{2}$-ICP)-MS gas blank spectrum from $6-60 \mathrm{~m} / \mathrm{z}$ is shown in Fig. 3a. The plasma species identified were mainly based on $\mathrm{N}, \mathrm{O}, \mathrm{C}$, and $\mathrm{Ar}$ from the $\mathrm{N}_{2}$ plasma gas and the ambient air. The most abundant species were ${ }^{14} \mathrm{~N}^{+}$and ${ }^{14} \mathrm{~N}^{16} \mathrm{O}^{+}$. To prevent detector saturation, these mass channels were not measured. The high abundance of ${ }^{14} \mathrm{~N}^{16} \mathrm{O}^{+}$indicated a strong influence of $\mathrm{O}_{2}$ from ambient air and/or impurities in the gas supplies on the $\mathrm{N}_{2}$ plasma. Other prominent species were ${ }^{14} \mathrm{~N}_{2}{ }^{+}$, ${ }^{16} \mathrm{O}_{2}{ }^{+},{ }^{40} \mathrm{Ar}^{+},{ }^{14} \mathrm{~N}_{3}{ }^{+}$, and ${ }^{14} \mathrm{~N}_{4}{ }^{+}$. The signal intensities of the nitrogen isotopologue ions ${ }^{14} \mathrm{~N}_{2}{ }^{+}-{ }^{14} \mathrm{~N}^{15} \mathrm{~N}^{+},{ }^{14} \mathrm{~N}_{3}{ }^{+}-{ }^{14} \mathrm{~N}_{2}{ }^{15} \mathrm{~N}^{+}$, and ${ }^{14} \mathrm{~N}_{4}{ }^{+}-{ }^{14} \mathrm{~N}_{3}{ }^{15} \mathrm{~N}^{+}$generally agreed with their natural abundances. This indicated that the formation of ${ }^{14} \mathrm{~N}_{x}{ }^{1} \mathrm{H}^{+}$species occurred to a lower extent. In addition to ${ }^{14} \mathrm{~N}^{15} \mathrm{~N}_{2}{ }^{+}$, the excess signal at $\mathrm{m} / \mathrm{z} 44$ was most likely caused by the formation of ${ }^{14} \mathrm{~N}_{2}{ }^{16} \mathrm{O}^{+}$while the signal $\mathrm{m} / \mathrm{z} 46$ was most probably due to ${ }^{14} \mathrm{~N}^{16} \mathrm{O}_{2}^{+}$.

The signal intensities at $\mathrm{m} / \mathrm{z} 36,38$ and 40 corresponded to the isotopic abundance of Ar. This suggested that Ar was still 

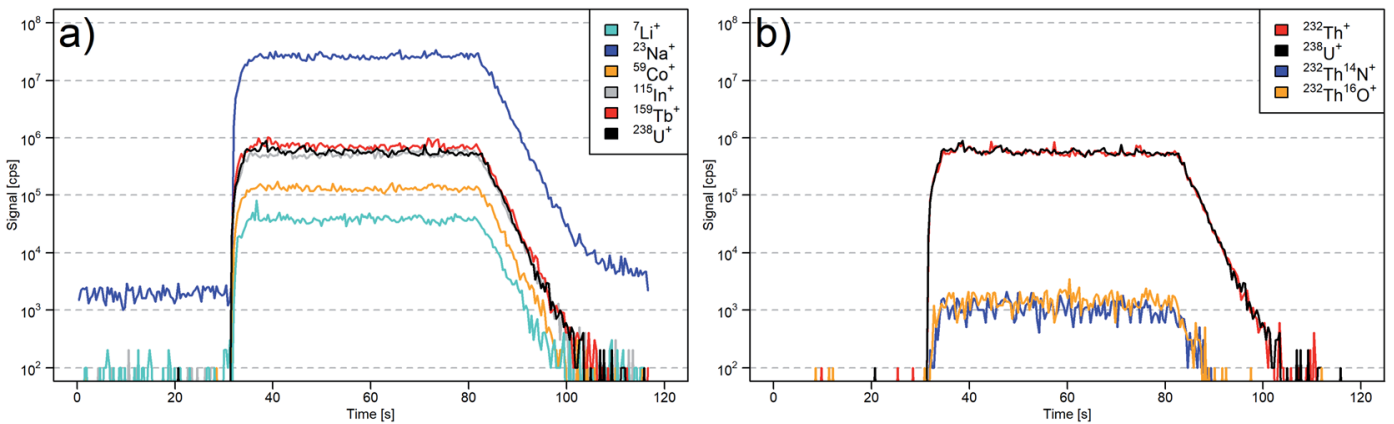

Fig. 1 LA-(N - ICP)-MS transient signals, where $30 \mathrm{~s}$ of gas blank were acquired followed by $50 \mathrm{~s}$ of ablation of NIST SRM 610. (a) Isotopes from 7-238 $\mathrm{m} / \mathrm{z}$. (b) Th, $U$, and Th clusters.
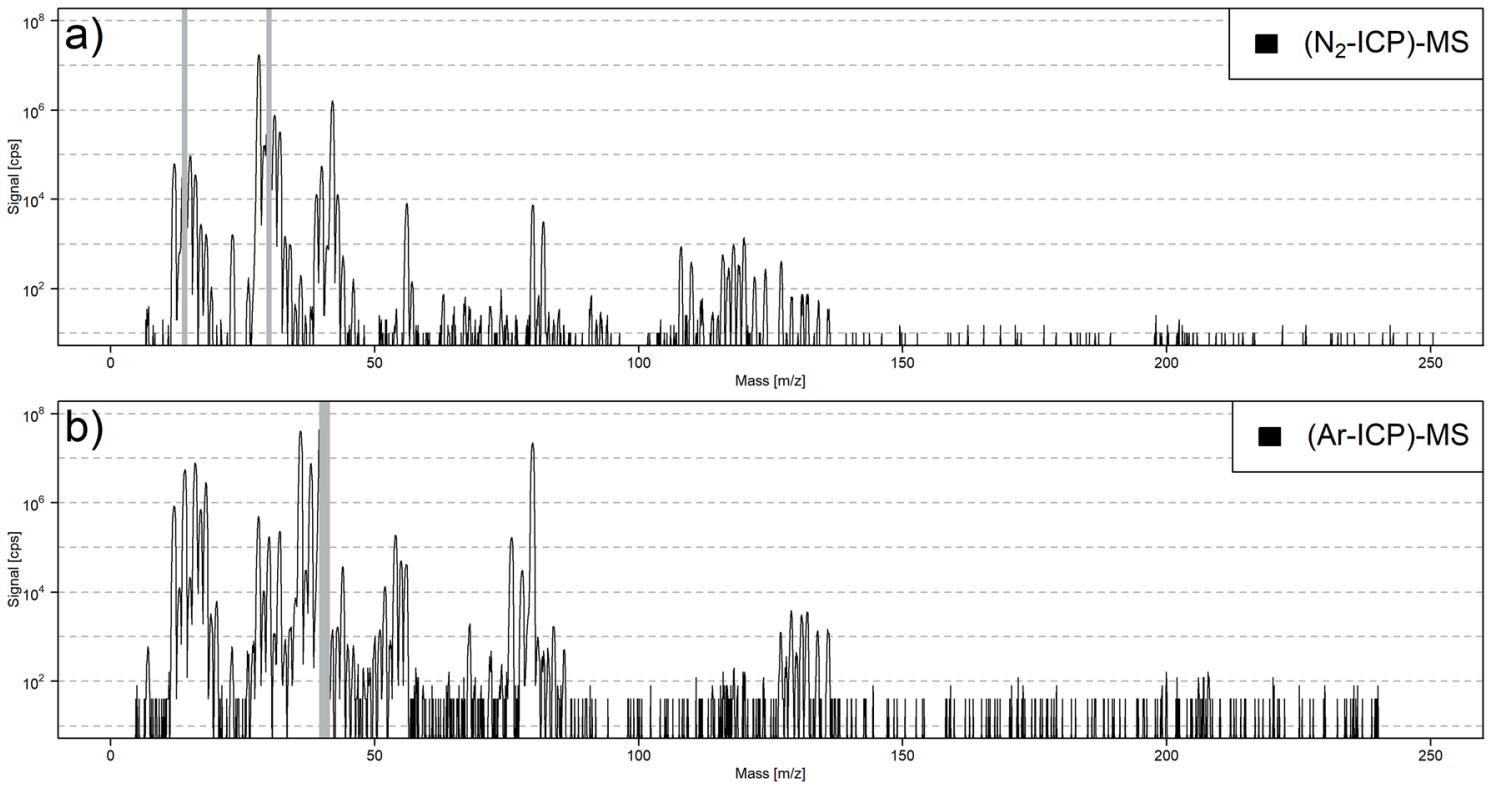

Fig. 2 Dry gas blank spectra of (a) ( $\left.\mathrm{N}_{2}-\mathrm{ICP}\right)-\mathrm{MS}$ and (b) (Ar-ICP)-MS. $\mathrm{m} / \mathrm{z} 14$ and 30 were not measured in the ( $\left.\mathrm{N}_{2}-\mathrm{ICP}\right)-\mathrm{MS}$ and $m / z 40$ and 41 were not measured in the (Ar-ICP)-MS to prevent detector saturation. The elevated noise in (b), especially in the range of $m / z>136$, can be explained with the lower integration time leading to single detected ions causing a higher cps intensity.

present in the $\mathrm{N}_{2}$ plasma. Therefore, another $\mathrm{N}_{2}$ source from a $50 \mathrm{~L}$ gas bottle (99.995\%, PanGas AG, Switzerland) was used for the plasma gas supply. The comparison of the gas blank spectra (ESI, Fig. S1a $\dagger$ ) of the ( $\mathrm{N}_{2}$-ICP)-MS gas blank using $\mathrm{N}_{2}$ from the $50 \mathrm{~L}$ gas bottle $(99.995 \%)$ and $\mathrm{N}_{2}$ from the liquid $\mathrm{N}_{2}$ Dewar $(>99.99 \%)$ revealed no substantial differences with the exception of a lower ion signal for $m / z 40$ in particular. This supports our assumption that the $\mathrm{N}_{2}$ supplies contained detectable amounts of Ar, where the higher signals observed when using the liquid $\mathrm{N}_{2}$ Dewar was due to continuous accumulation. As noble gases are usually not included in the purity specification for $\mathrm{N}_{2}$, the concentration of $\mathrm{Ar}$ in either supply remains unknown at this stage. However, considering that a $\mathrm{N}_{2}$ gas bottle (50 L, 200 bar) restricts to run the plasma for approximately one workday and the more expensive $\mathrm{N}_{2}$ from the bottle, all further experiments were carried out using $\mathrm{N}_{2}$ from the Dewar.

Additionally, substantial ion signals from $\mathrm{Sn}$ and Xe were observed in the ( $\mathrm{N}_{2}$-ICP)-MS gas blank (Fig. 3b). While Xe was most likely also contained in the $\mathrm{N}_{2}$ supply, the origin of $\mathrm{Sn}$ is not clear. Most likely it originated from contamination in the tubing, connectors or seals in the gas supply. Besides that, $\mathrm{Na}, \mathrm{K}$, and I were detected in the gas blank. However, elevated gas blanks for these elements are known from LA-(Ar-ICP)-MS experiments and related to memory effects from previous experiments.

Yet, there were notable signals at $\mathrm{m} / \mathrm{z} 80,82,108$ and 110 , which could not be assigned to any species. The mass difference of 28 indicated that the species at 108 and $110 \mathrm{~m} / \mathrm{z}$ are likely caused by ${ }^{14} \mathrm{~N}_{2}$ adducts from the species at 80 and $82 \mathrm{~m} / \mathrm{z}$, and similar intensity ratios for of $[80] /[82](2.4)$ and $[108] /[110](2.2)$ suggested a similar reactivity with $\mathrm{N}_{2} \cdot{ }^{40} \mathrm{Ar}_{2}{ }^{+} /{ }^{40} \mathrm{Ar}^{14} \mathrm{~N}_{3}{ }^{+}$, ${ }^{12} \mathrm{C}_{2}{ }^{14} \mathrm{~N}_{4}{ }^{+} /{ }^{12} \mathrm{C}^{14} \mathrm{~N}_{5}{ }^{+}$, and ${ }^{63} \mathrm{CuOH}^{+} /{ }^{65} \mathrm{CuOH}^{+}$were considered as possible combination for the ions formed at $m / z \quad 80$ and 82 . However, the ablation of copper, graphite, and the addition of Ar gas did not change the signal intensities of 80 and $82 \mathrm{~m} / \mathrm{z}$ significantly (ESI, Fig. S1b-d†). This suggested that C, Ar, and $\mathrm{Cu}$ were not the cause of these species. Further considerations 

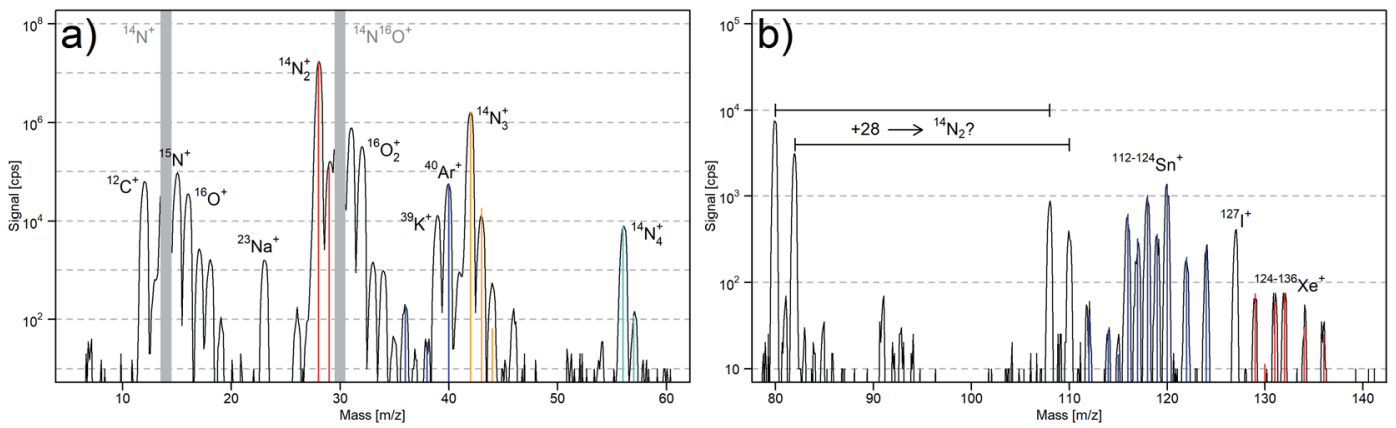

Fig. 3 Dry ( $\mathrm{N}_{2}$-ICP)-MS gas blank spectra. (a) Isotopic abundance of ${ }^{14} \mathrm{~N}_{2}-{ }^{14} \mathrm{~N}^{15} \mathrm{~N}$ (red), Ar (blue), ${ }^{14} \mathrm{~N}_{3}-{ }^{14} \mathrm{~N}_{2}{ }^{15} \mathrm{~N}-{ }^{14} \mathrm{~N}^{15} \mathrm{~N}_{2}$ (orange), and ${ }^{14} \mathrm{~N}_{4}-$ ${ }^{14} \mathrm{~N}_{3}{ }^{15} \mathrm{~N}$ (light blue). (b) Isotopic abundance of $\mathrm{Sn}$ (blue), Xe (red) and signals at $\mathrm{m} / \mathrm{z} 80,82,108$, and 110 not assigned yet.

about these unknown species are discussed in the ESI. $\dagger$ The copper experiment revealed the formation of other cluster species. ${ }^{63} \mathrm{Cu}^{14} \mathrm{~N}_{2}{ }^{+}$and ${ }^{65} \mathrm{Cu}^{14} \mathrm{~N}_{2}{ }^{+}$clusters $\left({ }^{63} \mathrm{Cu}^{14} \mathrm{~N}_{2}{ }^{+}{ }^{63} \mathrm{Cu}^{+}=\right.$ $0.02 \%$ ) and near the detection limit ${ }^{63} \mathrm{Cu}^{14} \mathrm{~N}^{+}$and ${ }^{65} \mathrm{Cu}^{14} \mathrm{~N}^{+}$ $\left({ }^{63} \mathrm{Cu}^{14} \mathrm{~N}^{+} /{ }^{63} \mathrm{Cu}^{+}=0.001 \%\right)$ were formed. Therefore, the formation of matrix nitride clusters must be kept in mind in further LA-( $\mathrm{N}_{2}$-ICP)-MS studies.

\section{Spectral interferences}

The most abundant isotopes ${ }^{40} \mathrm{Ca}^{+},{ }^{52} \mathrm{Cr}^{+},{ }^{56} \mathrm{Fe}^{+},{ }^{80} \mathrm{Se}^{+}$, and ${ }^{128} \mathrm{Te}^{+}$are commonly not measured in LA-(Ar-ICP)-MS as they suffer from plasma background ions, unless using a reaction cell or sector field mass spectrometers providing higher mass resolving power. ${ }^{14}$ Therefore, these elements were studied in more detail and the LODs of the isotopes were determined (ESI, Table S2 $\dagger$ ). ${ }^{40} \mathrm{Ca}^{+},{ }^{52} \mathrm{Cr}^{+},{ }^{56} \mathrm{Fe}^{+},{ }^{78} \mathrm{Se}^{+}$, and ${ }^{128} \mathrm{Te}^{+}$were found as the isotopes with lowest LOD analyzed using LA-( $\left.\mathrm{N}_{2}-\mathrm{ICP}\right)-\mathrm{MS}$. It is important to notice that the $\mathrm{N}_{2}$ gas supply contained $\mathrm{Ar}$ and caused a higher background intensity for ${ }^{40} \mathrm{Ca}^{+}$(Fig. 3a). The gas blank for $m / z 40$ could be reduced using $\mathrm{N}_{2}$ of higher purity (ESI, Fig. S1a $\dagger$ ) which would allow to further decrease the LOD for ${ }^{40} \mathrm{Ca}^{+}$. No plasma background ions were detected between $\mathrm{m} / \mathrm{z}$ 47 and 55 as well as between $\mathrm{m} / \mathrm{z} 58$ and 79 .

On the other hand, the gas blank signals from ${ }^{14} \mathrm{~N}_{4}{ }^{+}$hindered the achievement of an even lower LOD for ${ }^{56} \mathrm{Fe}^{+}$. The lowest LOD for Se was achieved using the isotope ${ }^{78} \mathrm{Se}^{+}$. The unknown $\left(\mathrm{N}_{2^{-}}\right.$ ICP)-MS gas blank species at 80 and $82 \mathrm{~m} / z$ enhanced the LODs for ${ }^{80} \mathrm{Se}^{+}$and ${ }^{82} \mathrm{Se}^{+}$. The lowest LOD for Te was achieved using ${ }^{128} \mathrm{Te}^{+}$. The gas blank signals for $\mathrm{Xe}^{+}$were reduced by approx. 50 times compared to LA-(Ar-ICP)-MS (Fig. 2).

\section{Limits of detection}

The LODs of 64 elements in NIST SRM 610 analyzed with LA$\left(\mathrm{N}_{2}\right.$-ICP)-MS are shown in Fig. 4 and the figures of merit were

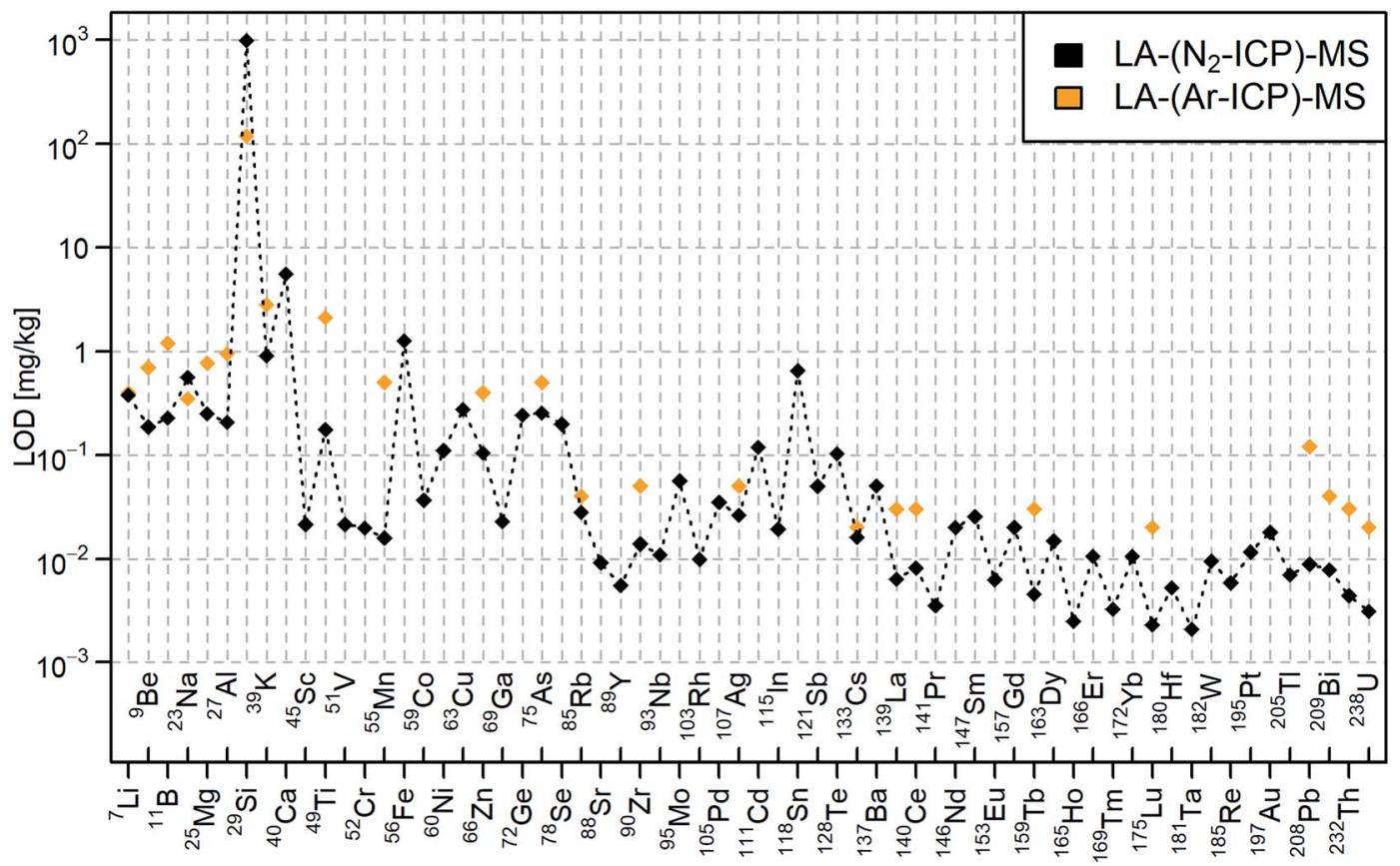

Fig. 4 LODs for NIST SRM 610 analyzed with LA-(N L $_{2}$ ICP)-MS (black) and LA-(Ar-ICP)-MS (orange) according to Günther et al. ${ }^{23}$ 


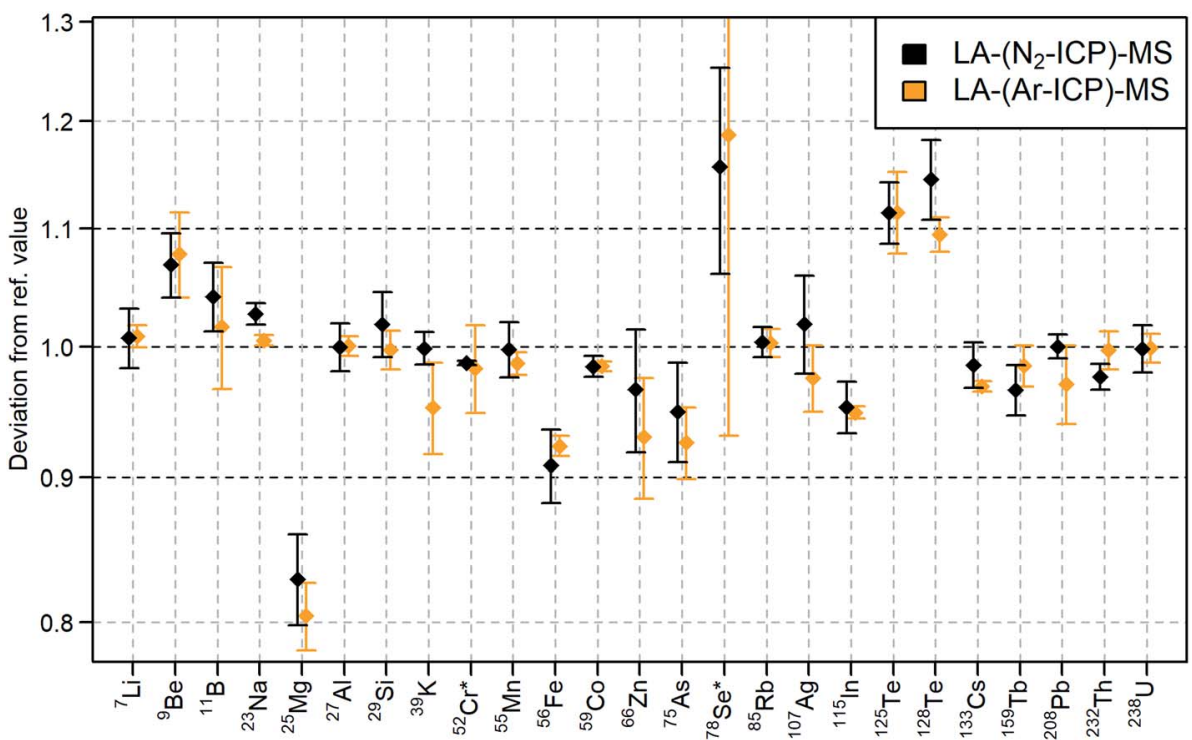

Fig. 5 Quantification of selected elements in NIST SRM 612 with LA-(N2-ICP)-MS (black) and LA-(Ar-ICP)-MS (orange) compared to their reference values ${ }^{38}$ according to ESI, Table S4.† For the LA-(Ar-ICP)-MS measurement ${ }^{53} \mathrm{Cr}^{+}$and ${ }^{77} \mathrm{Se}^{+}$were used instead of ${ }^{52} \mathrm{Cr}^{+}$and ${ }^{78} \mathrm{Se}^{+}$. The confidence intervals were calculated based on four consecutive measurements with a confidence level of $95 \%$.

summarized in ESI, Table S3. $\dagger$ LA-( $\mathrm{N}_{2}$-ICP)-MS provided in general lower LODs compared to Günther et al. ${ }^{23}$ who employed LA-(Ar-ICP)-MS with the same mass analyzer. However, it is important to note that different laser setting have been used. In this LA-( $\left.\mathrm{N}_{2}-\mathrm{ICP}\right)-\mathrm{MS}$ study a 2.25 times larger laser spot area and a 1.5-2 times lower laser fluence was used. Therefore, it is more important to demonstrate that very similar figures of merit can be achieved by using the ( $\mathrm{N}_{2}$-ICP)-MS. In contrast, the element analysis of ${ }^{39} \mathrm{~K}^{+},{ }^{40} \mathrm{Ca}^{+},{ }^{52} \mathrm{Cr}^{+},{ }^{55} \mathrm{Mn}^{+},{ }^{63} \mathrm{Cu}^{+},{ }^{78} \mathrm{Se}^{+}$, and ${ }^{128} \mathrm{Te}^{+}$ benefited from the reduction of the gas blank species and/or the applicability of a higher abundance isotope. The reduced gas blank at $55 \mathrm{~m} / \mathrm{z}$ based on ${ }^{40} \mathrm{Ar}^{15} \mathrm{~N}^{+}$and ${ }^{40} \mathrm{Ar}^{14} \mathrm{NH}^{+}$allowed the measurement of ${ }^{55} \mathrm{Mn}^{+}$at a 32-fold lower LOD compared to LA(Ar-ICP)-MS. Background intensities of $<5$ cps and 3-13 times lower LODs were measured for isotopes $\geq 137 \mathrm{~m} / \mathrm{z}$. The LOD for ${ }^{49} \mathrm{Ti}^{+}$and ${ }^{208} \mathrm{~Pb}^{+}$improved unexpectedly by $11-13$ times.

Higher LODs were obtained for ${ }^{23} \mathrm{Na}^{+},{ }^{29} \mathrm{Si}^{+}$, and ${ }^{118} \mathrm{Sn}^{+}$. The 1.6 times higher LOD for ${ }^{23} \mathrm{Na}^{+}$could be explained by memory effects of $\mathrm{Na}$ in the instrument. ${ }^{14} \mathrm{~N}^{15} \mathrm{~N}^{+}$from the nitrogen plasma background interfered with ${ }^{29} \mathrm{Si}^{+}$, which increased the LOD 8 times compared to LA-(Ar-ICP)-MS. ${ }^{14} \mathrm{~N}_{2}{ }^{+}$and ${ }^{14} \mathrm{~N}^{16} \mathrm{O}^{+}$in the gas blank interfered with the ${ }^{28} \mathrm{Si}^{+}$and ${ }^{30} \mathrm{Si}^{+}$isotopes. Contamination of Sn increased the gas blank intensity and therefore, the LOD for ${ }^{118} \mathrm{Sn}^{+}$. The LOD would be substantially reduced by removing the Sn contamination. Up to now, the Sn source could not be definitely located. Due to similar background intensities of ${ }^{14} \mathrm{~N}_{4}{ }^{+}$in LA-( $\mathrm{N}_{2}$-ICP)-MS and ${ }^{40} \mathrm{Ar}^{16} \mathrm{O}^{+}$in LA-(Ar-ICP)-MS, the LOD for ${ }^{56} \mathrm{Fe}^{+}$remained in a similar range.

In general, most of the LODs improved by 3-8 times compared to LA-(Ar-ICP)-MS. The elements with higher ionization potentials such as ${ }^{9} \mathrm{Be}^{+},{ }^{11} \mathrm{~B}^{+},{ }^{66} \mathrm{Zn}^{+}$, and ${ }^{75} \mathrm{As}^{+}$achieved similar improvements of the LODs when comparing elements with lower ionization potential such as ${ }^{27} \mathrm{Al}^{+},{ }^{85} \mathrm{Rb}^{+},{ }^{90} \mathrm{Zr}^{+}$, and
${ }^{238} \mathrm{U}^{+}$. This indicated similar ionization efficiency of the $\mathrm{N}_{2}$-ICP for laser-generated aerosols when compared to an Ar-ICP.

The non-metal elements $\mathrm{P}\left(413 \mathrm{mg} \mathrm{kg}^{-1}\right), \mathrm{S}\left(575 \mathrm{mg} \mathrm{kg}^{-1}\right)$, and $\mathrm{Cl}\left(274 \mathrm{mg} \mathrm{kg}^{-1}\right)$ in NIST SRM 610 were not detectable above LOD in the LA-( $\mathrm{N}_{2}$-ICP)-MS experiments. The interference of ${ }^{15} \mathrm{~N}^{16} \mathrm{O}^{+}$(approx. 800'000 cps) exacerbate the measurement of the monoisotopic ${ }^{31} \mathrm{P}^{+}$.

\section{Quantification}

NIST SRM 612 was analyzed with LA-(N $\left.\mathrm{N}_{2}-\mathrm{ICP}\right)-\mathrm{MS}$ and LA-(ArICP)-MS. Different isotopes were selected for the analysis

Table 2 Quantification of the REEs in BCR-2G with LA-( $\left.\mathrm{N}_{2}-I C P\right)-M S$ compared to their reference values. ${ }^{37}$ The confidence intervals were calculated based on four consecutive measurements with a confidence level of $95 \%$

\begin{tabular}{lccl}
\hline Isotope & $\begin{array}{l}\text { Quantified mass } \\
\text { fraction, }\left[\mathrm{mg} \mathrm{kg}^{-1}\right]\end{array}$ & $\begin{array}{l}\text { BCR-2G ref. values, } \\
{\left[\mathrm{mg} \mathrm{kg}^{-1}\right]}\end{array}$ & $\begin{array}{l}\text { Deviation from } \\
\text { ref. value }\end{array}$ \\
\hline${ }^{45} \mathrm{Sc}$ & $32.5 \pm 1.4$ & $33 \pm 2$ & $-2 \%$ \\
${ }^{89} \mathrm{Y}$ & $32.6 \pm 1.1$ & $35 \pm 3$ & $-7 \%$ \\
${ }^{139} \mathrm{La}$ & $24.4 \pm 0.4$ & $24.7 \pm 0.3$ & $-1 \%$ \\
${ }^{140} \mathrm{Ce}$ & $50.8 \pm 0.5$ & $53.3 \pm 0.5$ & $-5 \%$ \\
${ }^{141} \mathrm{Pr}$ & $6.6 \pm 0.7$ & $6.7 \pm 0.4$ & $-3 \%$ \\
${ }^{146} \mathrm{Nd}$ & $27.7 \pm 0.8$ & $28.9 \pm 0.3$ & $-4 \%$ \\
${ }^{147} \mathrm{Sm}$ & $6.5 \pm 0.5$ & $6.59 \pm 0.07$ & $-4 \%$ \\
${ }^{153} \mathrm{Eu}$ & $1.90 \pm 0.06$ & $1.97 \pm 0.02$ & $-7 \%$ \\
${ }^{157} \mathrm{Gd}$ & $6.7 \pm 0.3$ & $6.71 \pm 0.07$ & $0 \%$ \\
${ }^{159} \mathrm{~Tb}$ & $1.06 \pm 0.21$ & $1.02 \pm 0.08$ & $+3 \%$ \\
${ }^{163} \mathrm{Dy}$ & $6.3 \pm 0.3$ & $6.44 \pm 0.06$ & $-3 \%$ \\
${ }^{165} \mathrm{Ho}$ & $1.29 \pm 0.14$ & $1.27 \pm 0.08$ & $+1 \%$ \\
${ }^{166} \mathrm{Er}$ & $3.49 \pm 0.18$ & $3.70 \pm 0.04$ & $-6 \%$ \\
${ }^{169} \mathrm{Tm}$ & $0.51 \pm 0.03$ & $0.51 \pm 0.04$ & $0 \%$ \\
${ }^{172} \mathrm{Yb}$ & $3.34 \pm 0.20$ & $3.39 \pm 0.03$ & $-2 \%$ \\
${ }^{175} \mathrm{Lu}$ & $0.54 \pm 0.11$ & $0.503 \pm 0.005$ & $+8 \%$
\end{tabular}




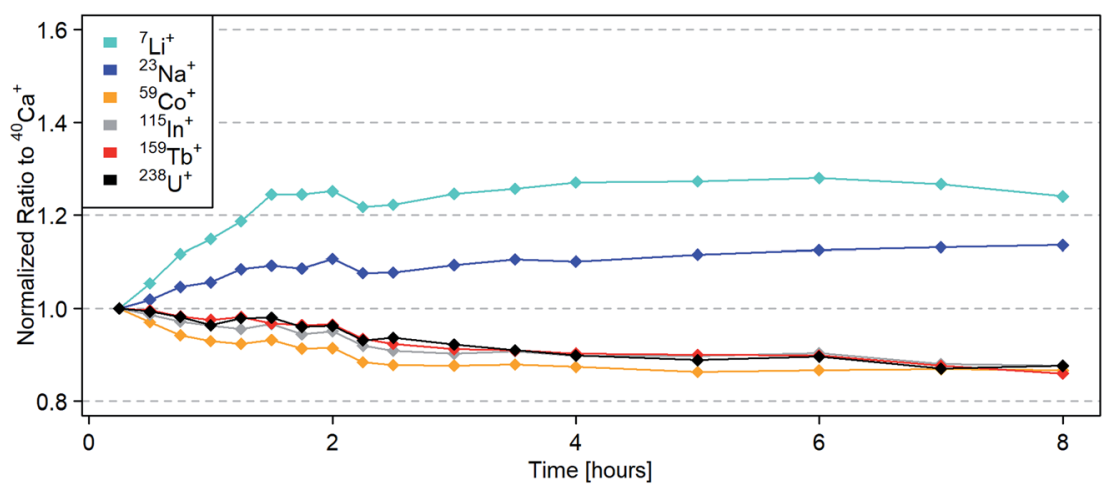

Fig. 6 Signal ratios to ${ }^{40} \mathrm{Ca}^{+}$normalized to the average of three NIST SRM 610 measurements after 15 minutes. Significant changes in signal ratios were observed in the first 1.5-2 hours. Afterwards, the signal ratios showed a stable trend with deviations below $5 \%$.

representing major elements $\left({ }^{23} \mathrm{Na}^{+},{ }^{27} \mathrm{Al}^{+},{ }^{29} \mathrm{Si}^{+},{ }^{40} \mathrm{Ca}^{+}\right)$, light elements $\left({ }^{7} \mathrm{Li}^{+},{ }^{9} \mathrm{Be}^{+},{ }^{11} \mathrm{~B}^{+},{ }^{25} \mathrm{Mg}^{+}\right)$, medium mass range elements $\left({ }^{55} \mathrm{Mn}^{+},{ }^{59} \mathrm{Co}^{+},{ }^{85} \mathrm{Rb}^{+},{ }^{107} \mathrm{Ag}^{+},{ }^{115} \mathrm{In}^{+}\right)$, heavy elements $\left({ }^{133} \mathrm{Cs}^{+}\right.$, $\left.{ }^{159} \mathrm{~Tb}^{+},{ }^{208} \mathrm{~Pb}^{+},{ }^{232} \mathrm{Th}^{+},{ }^{238} \mathrm{U}^{+}\right)$, elements with high first ionization potentials $\left({ }^{9} \mathrm{Be}^{+},{ }^{11} \mathrm{~B}^{+},{ }^{29} \mathrm{Si}^{+},{ }^{66} \mathrm{Zn}^{+},{ }^{78} \mathrm{Se}^{+},{ }^{75} \mathrm{As}^{+},{ }^{125 / 128} \mathrm{Te}^{+}\right)$and elements which are influenced by interferences in LA- $\left(\mathrm{N}_{2}\right.$-ICP)MS and/or LA-(Ar-ICP)-MS $\left({ }^{29} \mathrm{Si}^{+},{ }^{39} \mathrm{~K}^{+},{ }^{40} \mathrm{Ca}^{+},{ }^{52} \mathrm{Cr}^{+},{ }^{55} \mathrm{Mn}^{+}\right.$, $\left.{ }^{56} \mathrm{Fe}^{+},{ }^{78} \mathrm{Se}^{+},{ }^{125 / 128} \mathrm{Te}^{+}\right)$. The elements through all the mentioned groups above were quantified using LA-( $\mathrm{N}_{2}$-ICP)-MS within \pm $10 \%$ with respect to their reference values (Fig. 5). ${ }^{38}$ Exceptions were ${ }^{25} \mathrm{Mg}^{+},{ }^{78} \mathrm{Se}^{+}$, and ${ }^{125 / 128} \mathrm{Te}^{+}$, but their quantification using LA-(Ar-ICP)-MS resulted in a very similar bias (ESI, Table S4†). This indicated once more, that laser-generated aerosols behave very similar within the nitrogen plasma compared to the argon plasma.

In order to evaluate the accuracy of the LA-( $\left.\mathrm{N}_{2}-\mathrm{ICP}\right)-\mathrm{MS}$ analyses for low mass fractions, the rare earth elements (REEs) in BCR-2G with mass fractions of $0.5-54 \mathrm{mg} \mathrm{kg}^{-1}$ were quantified using NIST SRM 610 as an external standard. ${ }^{40} \mathrm{Ca}^{+}$ was used as internal standard. LA-( $\mathrm{N}_{2}$-ICP)-MS operating conditions were used according to Table 1 . As reported in Table 2, LA-( $\mathrm{N}_{2}$-ICP)-MS allowed the quantification of sub-mg kg ${ }^{-1}$ of REEs in BCR-2G within $\pm 10 \%$ regarding the reference values. ${ }^{37}$ This demonstrated the capability of LA-( $\left.\mathrm{N}_{2}-\mathrm{ICP}\right)-\mathrm{MS}$ for trace element analysis.

\section{Long-term stability}

The long-term stability of LA-( $\mathrm{N}_{2}$-ICP)-MS was investigated over 8 hours using NIST SRM 610. Each data point represents the average of three measurements. The plasma was started, optimized and the first measurements were taken after 15 minutes. Afterwards, the operation parameters remained unchanged over the entire measurement campaign. For the first 2.5 hours, measurements were repeated every 15 minutes, then every 30 minutes for 1.5 more hours, then every 60 minutes for another 4 hours. $\mathrm{As}^{40} \mathrm{Ca}^{+}$was used as an internal standard in this study, the signal ratios to ${ }^{40} \mathrm{Ca}^{+}$were determined and then normalized to the first measurements. During the first 1.5 hours, a larger difference in intensity ratios (Fig. 6) was observed, as for example an increase of $25 \%$ for ${ }^{7} \mathrm{Li}^{+} /{ }^{40} \mathrm{Ca}^{+}$. In general, intensity ratios increased for lighter elements while heavier elements showed a decrease. This implied a mass dependent instrumental drift during warmup. After approx. two hours, the intensity ratios stabilized and variations remained below $5 \%$. The drift of intensity ratios is known from LA-(Ar-ICP)-MS and was already taken care of using a time dependent quantification strategy for LA-(Ar-ICP)-MS. ${ }^{42}$ This approach was also applied in the quantification of NIST SRM 612 and BCR-2G using LA- $\left(\mathrm{N}_{2^{-}}\right.$ ICP)-MS.

However, the ${ }^{232} \mathrm{Th}^{14} \mathrm{~N}^{+} / 232 \mathrm{Th}^{+}$ratio was stable over the entire measurement campaign at $0.2 \%$. The ${ }^{232} \mathrm{Th}^{16} \mathrm{O}^{+} / 232 \mathrm{Th}^{+}$ ratio started at $0.4 \%$ and decreased over time until it remained stable at $0.2 \%$ after two hours (ESI, Fig. S2 $\dagger$ ). The elevated ${ }^{232} \mathrm{Th}^{16} \mathrm{O}^{+} / 232 \mathrm{Th}^{+}$ratio in the beginning could derive from remaining residues of $\mathrm{O}_{2}$ in the ablation cell.

\section{Conclusion}

LA-( $\mathrm{N}_{2}$-ICP)-MS is a sensitive technique and suitable for the quantification of major to trace elements. In general, it achieved similar or even lower LODs compared to LA-(Ar-ICP)-MS. These general improvements are of lower importance than the fact that it could be demonstrated that same order of magnitude LODs can be achieved using a nitrogen plasma in comparison to an argon-sustained plasma. However, the LODs of $\mathrm{K}, \mathrm{Ca}, \mathrm{Ti}, \mathrm{Cr}$, $\mathrm{Mn}, \mathrm{Cu}, \mathrm{Se}, \mathrm{Te}$, and $\mathrm{Pb}$ were significantly improved when comparing the results to a similar (Ar-ICP)-MS system. On the other hand, the LODs for the analysis of $\mathrm{Si}, \mathrm{P}$, and $\mathrm{Sn}$ were significantly increased when comparing to LA-(Ar-ICP)-MS due to the plasma gas generated cluster ions and impurities of Sn. The LOD for Sn could be improved by removing this contamination in the gas supply. The LOD for Fe remained at a similar level for LA-( $\mathrm{N}_{2}$-ICP)-MS and LA-(Ar-ICP)-MS. The interference of ${ }^{14} \mathrm{~N}_{4}{ }^{+}$in LA-( $\mathrm{N}_{2}$-ICP)-MS and ${ }^{40} \mathrm{Ar}^{16} \mathrm{O}^{+}$in LA-(Ar-ICP)-MS did not allow the measurement of ${ }^{56} \mathrm{Fe}^{+}$at a lower LOD as for example for V or Co.

As demonstrated, the gas blank of the $\left(\mathrm{N}_{2}\right.$-ICP)-MS contained significantly less interferences originating from plasma species when compared to the (Ar-ICP)-MS. Cluster ions formed as argides were not observed when using the nitrogen plasma source. However, nitride cluster ions were formed and need to 
be considered in further studies. Most of the gas blank signals can be explained by the respective cluster ions. The origin of the ions at $\mathrm{m} / \mathrm{z} 80,82,108$, and 110 remained unknown. The $\left(\mathrm{N}_{2}-\right.$ ICP)-MS was stable after 1.5-2 hours of warm up time.

Overall, LA-( $\left.\mathrm{N}_{2}-\mathrm{ICP}\right)-\mathrm{MS}$ provided a very similar performance in comparison to LA-(Ar-ICP)-MS and achieved similar vaporization, atomization and ionization efficiencies for lasergenerated aerosols. In contrast to LA-(Ar-ICP)-MS, various isotopes benefit from the absence of argon as plasma gas in LA$\left(\mathrm{N}_{2}\right.$-ICP)-MS, especially in the mass range below $m / z 80$. Considering operating cost of the MICAP plasma source, LA$\left(\mathrm{N}_{2}\right.$-ICP)-MS has a high potential to compete with or even replace LA-(Ar-ICP)-MS in the future.

\section{Conflicts of interest}

There are no conflicts to declare.

\section{Acknowledgements}

The authors acknowledge the support from Ashok Menon and Jovan Jevtic of Radom Corp. and the financial support through the Swiss National Science Foundation, project number SNF 200021_197224.

\section{References}

1 R. S. Houk, V. A. Fassel, G. D. Flesch, H. J. Svec, A. L. Gray and C. E. Taylor, Anal. Chem., 1980, 52, 2283-2289.

2 A. L. Gray, Analyst, 1985, 110, 551-556.

3 D. Günther and B. Hattendorf, TrAC, Trends Anal. Chem., 2005, 24, 255-265.

4 R. J. Reeder and J. C. Grams, Geochim. Cosmochim. Acta, 1987, 51, 187-194.

5 C. I. Prince, J. Kosler, D. Vance and D. Günther, Chem. Geol., 2000, 168, 255-274.

6 J. S. Becker, M. V. Zoriy, C. Pickhardt, N. Palomero-Gallagher and K. Zilles, Anal. Chem., 2005, 77, 3208-3216.

7 R. W. Hutchinson, A. G. Cox, C. W. McLeod, P. S. Marshall, A. Harper, E. L. Dawson and D. R. Howlett, Anal. Biochem., 2005, 346, 225-233.

8 C. Latkoczy, S. Becker, M. Dücking, D. Günther, J. Hoogewerff, J. Almirall, J. Buscaglia, A. Dobney, R. D Koons, S. Berends-Montero, G. J. Q. van der Peijl, W. R. S. Stoecklein, T. Trejos, J. Watling and V. S Zdanowicz, J. Forensic Sci., 2005, 50, 1327-1341.

9 C. Giesen, H. A. O. Wang, D. Schapiro, N. Zivanovic, A. Jacobs, B. Hattendorf, P. J. Schüffler, D. Grolimund, J. M. Buhmann, S. Brandt, Z. Varga, P. J. Wild, D. Günther and B. Bodenmiller, Nat. Methods, 2014, 11, 417.

10 A. Gundlach-Graham, M. Burger, S. Allner, G. Schwarz, H. A. O. Wang, L. Gyr, D. Grolimund, B. Hattendorf and D. Günther, Anal. Chem., 2015, 87, 8250-8258.

11 M. Burger, A. Gundlach-Graham, S. Allner, G. Schwarz, H. A. Wang, L. Gyr, S. Burgener, B. Hattendorf, D. Grolimund and D. Gunther, Anal. Chem., 2015, 87, 8259-8267.
12 S. H. Tan and G. Horlick, Appl. Spectrosc., 1986, 40, 445-460. 13 K. Oishi, T. Okumoto, T. Iino, M. Koga, T. Shirasaki and N. Furuta, Spectrochim. Acta, Part B, 1994, 49, 901-914.

14 T. W. May and R. H. Wiedmeyer, At. Spectrosc., 1998, 19, 150155.

15 T. Ohno, Y. Muramatsu, Y. Shikamori, C. Toyama, N. Okabe and H. Matsuzaki, J. Anal. At. Spectrom., 2013, 28, 1283-1287.

16 L. Balcaen, E. Bolea-Fernandez, M. Resano and F. Vanhaecke, Anal. Chim. Acta, 2015, 894, 7-19.

17 J. S. Becker and H. J. Dietze, Fresenius. J. Anal. Chem., 1997, 359, 338-345.

18 S. Hirata, H. Toshimitsu and M. Aihara, Anal. Sci., 2006, 22, 39-43.

19 M. Schild, A. Gundlach-Graham, A. Menon, J. Jevtic, V. Pikelja, M. Tanner, B. Hattendorf and D. Günther, Anal. Chem., 2018, 90, 13443-13450.

20 P. R. D. Mason and W. J. Kraan, J. Anal. At. Spectrom., 2002, 17, 858-867.

21 Z. Yang, S. E. Jackson, L. J. Cabri, P. Wee, H. P. Longerich and M. Pawlak, J. Anal. At. Spectrom., 2020, 35, 534-547.

22 B. Hattendorf and D. Günther, J. Anal. At. Spectrom., 2000, 15, 1125-1131.

23 D. Günther, B. Hattendorf and A. Audétat, J. Anal. At. Spectrom., 2001, 16, 1085-1090.

24 C. I. M. Beenakker, Spectrochim. Acta, Part B, 1976, 31, 483486.

25 Y. Okamoto, M. Yasuda and S. Murayama, Jpn. J. Appl. Phys., 1990, 29, L670-L672.

26 M. R. Hammer, Spectrochim. Acta, Part B, 2008, 63, 456-464. 27 D. Zhu, W. Jin, B. Yu, Y. Ying, H. Yu, J. Shan, Y. Yan, C. Xu, B. Wang and Q. Jin, Chem. Res. Chin. Univ., 2017, 33, 709713.

28 D. A. Wilson, G. H. Vickers and G. M. Hieftje, Anal. Chem., 1987, 59, 1664-1670.

29 W.-L. Shen, T. M. Davidson, J. T. Creed and J. A. Caruso, Appl. Spectrosc., 1990, 44, 1003-1010.

30 Y. Okamoto, J. Anal. At. Spectrom., 1994, 9, 745-749.

31 J. Jevtic, A. Menon and V. Pikelja, US Pat., PCT/US2014/ 024306, 2014.

32 G. W. Dickinson and V. A. Fassel, Anal. Chem., 1969, 41, 1021-1024.

33 A. J. Schwartz, Y. Cheung, J. Jevtic, V. Pikelja, A. Menon, S. J. Ray and G. M. Hieftje, J. Anal. At. Spectrom., 2016, 31, 440-449.

34 H. Wiltsche and M. Wolfgang, J. Anal. At. Spectrom., 2020, 35, 2369-2377.

35 J. Koch, M. Wälle, R. Dietiker and D. Günther, Anal. Chem., 2008, 80, 915-921.

36 S. M. Eggins, L. P. J. Kinsley and J. M. G. Shelley, Appl. Surf. Sci., 1998, 127-129, 278-286.

37 K. P. Jochum and U. Nohl, Chem. Geol., 2008, 253, 50-53.

38 K. P. Jochum, U. Weis, B. Stoll, D. Kuzmin, Q. Yang, I. Raczek, D. E. Jacob, A. Stracke, K. Birbaum, D. A. Frick, D. Günther and J. Enzweiler, Geostand. Geoanal. Res., 2011, 35, 397-429.

39 M. B. Fricker, PhD thesis, ETH Zurich, 2012. 
40 RStudioTeam, RStudio: Integrated Development for $R$, RStudio Inc., Boston, MA, 2019.

41 RCoreTeam, $R$ : A Language and Environment for Statistical Computing, R Foundation for Statistical Computing, Vienna, Austria, 2020.
42 H. P. Longerich, S. E. Jackson and D. Gunther, J. Anal. At. Spectrom., 1996, 11, 899-904.

43 B. Hattendorf, C. Latkoczy and D. Günther, Anal. Chem., 2003, 75, 341a-347a. 